Acta Cryst. (2002). A58 (Supplement), C24

SIZE-STRAIN ROUND ROBIN: FIRST RESULTS AND THE COMPARATIVE ANALYSIS OF THE MEASUREMENTS

D. Balzar ${ }^{1}$ N. Audebrand ${ }^{2}$ M. R. Daymond ${ }^{3}$ A. Fitch ${ }^{4}$ A. Hewat ${ }^{5}$ J. I. Langford ${ }^{6}$ A. Le Bail $^{7}$ D. Louer ${ }^{2}$ O. Masson ${ }^{4}$ N. C. Popa ${ }^{8}$ P. W. Stephens ${ }^{9}$ B. Toby ${ }^{10}$

${ }^{1}$ University of Denver and NIST, Boulder, Colorado, U.S.A. ${ }^{2}$ University of Rennes, Rennes, France ${ }^{3}$ ISIS, Rutherford-Appleton Laboratory, Didcot, U.K. ${ }^{4}$ ESRF, Grenoble, France ${ }^{5}$ ILL, Grenoble, France ${ }^{6}$ University of Birmingham, Birmingham, U.K. ${ }^{7}$ University of Maine, Le Mans, France ${ }^{8}$ National Institute for Materials Physics, Bucharest, Romania ${ }^{9}$ NSLS, Brookhaven National Laboratory, Upton, New York, U.S.A. ${ }^{10}$ NCNR, NIST, Gaithersburg, Maryland, U.S.A

The effects of local lattice strains and small coherently diffracting domains on diffraction lines remain insufficiently characterized. To assess the accuracy of the domain size and lattice strain determination, a round robin was organized under the auspices of the Commission on Powder Diffraction. The sample (cubic-ceria powder) was synthesized at the University of Rennes. Because many methods of line-broadening analysis yield sometimes contradictory results, and to accurately assess the physical part of line broadening irrespective of the instrument, measurements were collected with the following instruments: (i) University of Le Mans: a "common" x-ray laboratory setup; (ii) University of Birmingham: a high-resolution x-ray laboratory setup with an incident-beam monochromator; (iii) X3B1 beamline at NSLS: 2nd-generation synchrotron, flat-plate geometry; (iv) BM16 beamline at ESRF: 3rd-generation synchrotron, capillary geometry; (v) BT1 instrument at NCNR and D1A instrument at ILL: constant-wavelength neutron sources; (vi) HRPD instrument at ISIS: Time-of-flight neutron source. These measurements were made available to the round-robin participants. They conducted linebroadening analysis through different routes, including integral-breadth, Fourierdeconvolution, and Rietveld-refinement methods. The round-robin results showed: (i) The ceria powder shows predominantly domain-size related isotropic line broadening; (ii) Sizebroadened profile is not pure Lorentzian but has a strong Gaussian contribution; (iii) The results obtained with different methods do not vary considerably, which is probably a consequence of a strain-free specimen. We also report on the analysis of the measurements using a physical model based on lognormal size distribution of spherical crystallites, which agrees well with the phenomenological approaches.

Keywords: LINE BROADENING, RIETVELD REFINEMENT, ROUND ROBIN

Acta Cryst. (2002). A58 (Supplement), C24

\section{NEW APROACH TO RESIDUAL STRESSES AND PHASE ANALYSIS DUE TO GRAZING ANGLE X-RAY DIFFRACTION GEOMETRY} S. Skrzypek ${ }^{1}$ W. Ratuszek ${ }^{1}$ A. Baczmanski

University of Mining And Metallurgy Pysical And Powder Metallurgy Al.Mickiewicza 30 KRAKOW 30-059 POLAND

Various kinds of fatigue experiments and machining of heat-treated steels or other materials having metastable phase can cause phase transformation and/or plastic deformation in surface layer. It is connected with volume change and additional deformation due to machining creates residual macro-stresses. The residual stresses distribution is gradient-like in mostly similar cases. An application of classical X-ray diffraction $\sin ^{2} \psi$ method in these kinds of samples makes some problems in term of real value of residual macro-stresses. Theoretical calculation and measurement of residual macro-stresses and volume fraction of retained austenite in carburized toothed wheels were curried out. Grinding and mechanical fatigue of gear wheels caused big compressive residual stresses and phase transformation of retained austenite in surface layer. An application of $\mathrm{g}-\sin ^{2} \psi$ method, which is based on grazing angle X-ray diffraction geometry, made possible to get real value of residual macro-stresses and additionally could be suitable in estimation of their gradient-like distribution. An application of this geometry to X-ray diffraction phase analysis made possible to get retained austenite distribution versus thickness under surface as well.

\section{Keywords: RESIDUAL STRESSES PHASE ANALYSIS GRAZING} ANGLE X-RAY DIFFRACTION
Acta Cryst. (2002). A58 (Supplement), C24

\section{MICROBEAM X-RAY DIFFRACTION MEASUREMENT OF STRAIN} I. C. Noyan

IBM Research Division P.O. Box 218 YORKTOWN HEIGHTS NY 10598 USA

The availability of high brilliance synchrotron sources and focusing $\mathrm{x}$-ray optics have facilitated the measurement of local stresses and strains in domains that are micrometers or smaller in size. Since the features of interest in microelectronics fall within this range, microbeam techniques are frequently used in analyzing ULSI devices. Currently there are several techniques that are utilized for such measurements. Some are similar to the macroscopic techniques (such as $\sin ^{2} c$ ) that are used in bulk measurements, and use the spacing of atomic planes to determine strains in various directions. These strains are then transformed to get the strain and stress in the sample coordinates. This approach can be implemented with monochromatic or polychromatic radiation. Another technique utilizes topographic mapping of a strong reflection from the substrate, and yields relative stress/strain contours. A third alternative is to measure the local curvature of the sample using either monochromatic or polychromatic radiation. All techniques yield complementary data, and should be used together where possible. Unfortunately, this is not a trivial task since their instrumental requirements are significantly different. In this talk, I will discuss the challenges of stress determination from micro-domains. Topographic determination of real-time stress/strain changes in thin-film wires undergoing electromigration and curvature measurements from bent $\mathrm{Si}$-strips will be presented to illustrate these points.

\section{Keywords: MICRODIFFRACTION MICROTOPOGRAPHY} ELECTROMIGRATION

\section{Acta Cryst. (2002). A58 (Supplement), C24}

\section{MEASURING STRAIN IN INDIVIDUAL GRAINS OF CVD DIAMOND} M. Golshan ${ }^{1}$ D. Laundy ${ }^{1}$ M. Moore ${ }^{2}$ P.F. Fewster ${ }^{3}$ J.E. Butler ${ }^{4}$

${ }^{1}$ CLRC, Daresbury Laboratory, Warrington, Cheshire, WA4 4AD, UK. ${ }^{2}$ Royal Holloway University of London, Egham, Surrey, TW20 0EX, UK. ${ }^{3}$ Philips Analytical Research Centre, Cross Oak Lane, Redhill RH1 5HA, UK ${ }^{4}$ Naval Research Laboratory, Washington D.C. 20375, USA.

The ability to produce diamond coatings and freestanding layers by chemical vapor deposition (CVD) methods is one of the most exciting advances in materials science. The quality of the diamond continues to improve, but the strength properties are still not fully optimized. Quantifying strain within the individual crystallites in CVD diamond films is therefore of crucial importance in the technological advancement of these materials. Here we have applied various diffraction techniques to study individual grains in polished and asgrown polycrystalline CVD diamond films, which had been grown using a microwave plasma technique. Three-dimensional reciprocal-space mapping was performed to determine the true microstrain: that is, the distribution of strain within individual grains: and to calculate the precise lattice parameter and deviation from near-perfect samples. In order to accomplish this, Bragg reflections from individual grains were isolated. This was achieved by increasing the $2 \theta$ resolution and by reducing the axial divergence of the beam, resulting in a smaller probe and partially eliminating the effect of projection on to the diffraction plane along the perpendicular direction. A suitable divergence was achieved by using two pairs of slits, placed after the monochromator and before the detector respectively. The experiments were carried out at Daresbury Laboratory Stations 16.3 and 2.3, and at ESRF ID10 B. The results obtained from three different grades of CVD diamond films were compared. The role of nitrogen as an n-dopant in diamond, and its effect on strain and texture of the films was also investigated.

Keywords: SYNCHROTRON, CVD DIAMOND, DIFFRACTION 